\title{
Heat IIIness: A Comparison Between UK and Cyprus Reports
}

\author{
Maj MCM Bricknell \\ MRCGP, DRCOG, RAMC \\ Centre for Human Sciences, Defence Research Agency, Farnborough GU14 6TD
}

SUMMARY: This paper presents an analysis of the reports of heat casualties to Medical Branch, United Kingdon? Land Forces (UKLF) for the period 1986-1994. There was a marked reduction in reports for 1990-1993 compared음 to the remaining period studied. This may have been the result of improved prevention or under-reporting. This data has been compared to the reports of heat casualties occurring in Cyprus from 1990-1994. Forced marches and $\mathbb{R}$ military runs were the primary activities causing heat casualties in UK compared to military exercises in Cyprus® There were many more severe casualties in UK than in Cyprus. If it is necessary to reduce the annual rate of heatcasualties in the Army then changes in policy should be focused on the problem in UK. This should consider the generation of metabolic heat as the primary cause of heat illness as opposed to environmental factors. In overseas $\vec{w}$ commands (eg Cyprus) the relative effects are reversed.

\section{Introduction}

Death or injury as' a consequence of heat illness is a potentially avoidable tragedy. The epidemiology of heat casualties in the British Armed Forces is difficult to define because there is no centrally co-ordinated reporting system. A retrospective analysis of hospital admissions showed an average of 135 Service persons admitted annually (1). However it is suggested that these hospital based figures may underestimate the annual incidence by at least $29 \%$ (2). There is no published data for heat casualties in the UK based on reports from primary care.

Current instructions for the prevention of heat injury are based on Defence Council Instruction JS 94 published in 1990(3). If these instructions are to be revised it is important to establish the epidemiology of heat illness in the Army to identify factors causing heat casualties that are amenable to prevention. It is the perception of some non-military commentators that heat casualties are entirely preventable (4). Therefore they may consider that a heat casualty will only occur if there has been negligence. Consequently the prevention of heat casualties justifies a high priority.

The aim of this paper is to present the results of an analysis of reports of heat casualties occurring in the UK. This information has been collated in the same manner as a previous analysis of heat casualty reports originating in Episkopi, Cyprus. The results from the two different Army Commands have then been compared.

\section{Method}

All heat casualty reports held at the Medical Branch, Headquarters United Kingdom Land Forces (UKLF) for 1990-1994 were retrieved. These reports should be initiated by any medical unit that treats a heat casualty within the UKLF Command. They are then passed through the medical branch of the local military district headquarters for onward transmission to the medical branch at UKLF. The system requires the identifying details of the casualty, the activity on which employed and the disposal of the casualty to be reported. There is nc system for cross-checking the reliability of the returns.

The results from a previous study for 1986-1989 (5 were included in the analysis. The heat casualty data from Cyprus is based on the reports originating from the Garrison Medical Centre at Episkopi for 1990-1994. This has previously been analysed in detail and this analy was available for comparison (6).

\section{Results}

A total of 490 heat casualties were reported to Medi $\overrightarrow{8} \overrightarrow{8}$ Branch, United Kingdom Land Forces in the period 1986 \% 1994. In Episkopi, Cyprus there were 97 reports frim 1990-1994. The breakdown of these reports by yeadi shown in Table 1. There is a clear variation in numbers per year with the reports for 1990-1993 bein substantially less than those for the preceding years. Th $\mathbb{Q}$ reports came from a wide range of different units. The unit information has not been presented because th옹 substantial turbulence in the organisation of UKLF during the period studied precludes any worthwhile interpretatiorof of the information. These figures are compared with total of 97 reports from Cyprus during the period 1990 . 1994.

Table 1

\begin{tabular}{|c|c|c|c|c|c|c|c|c|c|c|}
\hline \multicolumn{11}{|c|}{ Heat Casualty Reports } \\
\hline Year & 1986 & 1987 & 1988 & 1989 & 1990 & 1991 & 1992 & 1993 & 1994 & Total \\
\hline $\begin{array}{l}\text { UKLF } \\
\text { Cyprus }\end{array}$ & 71 & 91 & 98 & 111 & $\begin{array}{l}17 \\
23\end{array}$ & $\begin{array}{l}8 \\
7\end{array}$ & $\begin{array}{l}7 \\
2\end{array}$ & $\begin{array}{c}6 \\
27\end{array}$ & $\begin{array}{l}81 \\
37\end{array}$ & $\begin{array}{r}490 \\
97\end{array}$ \\
\hline
\end{tabular}

The reports for 1986-1989 for UKLF are only available as total numbers so further analysis is based on the datin from 1990-1994. In all figures the comparison is shown an a percentage of the total for each group. The monthly distribution of heat casualties is compared between UK 
and Cyprus in Figure 1. It can be seen that the seasonal variation shows a marked similarity between the two Commands. This is expected as both are in the northern hemisphere and therefore have concurrent summers. It is important to note that heat casualties are reported during the winter months in both locations in spite of low environmental temperatures.

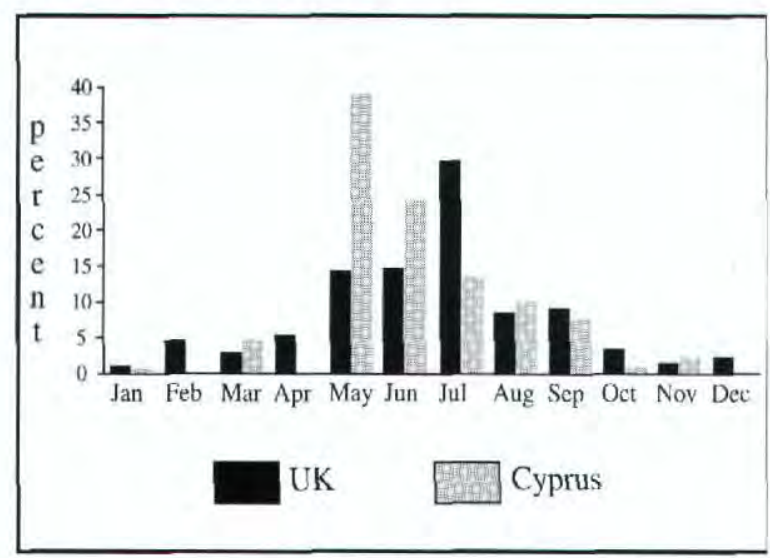

Fig 1. Monthly Distribution of Casualties UK and Cyprus

The reports from UK for 1990-1993 were substantially lower than the previous years and 1994. It was considered that this was most likely to represent a reporting bias rather than a true drop in incidence. The remaining UK/Cyprus comparisons are based on the UK reports for 1994. The comparison between the activities causing heat casualties is shown in Figure 2. There is a marked variation between the two groups with military runs and marches causing the most casualties in UK and military exercises causing the majority of casualties in Cyprus. The Infantry Combat Fitness Test (ICFT) is a significant individual cause of casualties in both groups.

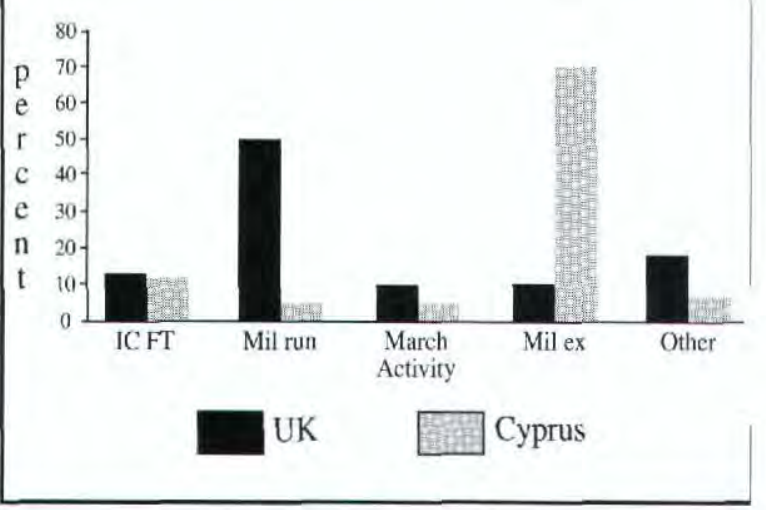

Fig 2. ACTIVITY UK and Cyprus
A comparison between the reported severity of cases is shown in Figure 3. The definition for each group is alsoz shown. The classification of mild cases included any@̊ admissions to a Medical Reception Station (MRS) in UKO whereas the Cyprus analysis is based on reports from? Episkopi which does not have a MRS facility. The UK? reporting system does not require clinical information to be $\overrightarrow{\vec{F}}$ included however in many cases there were comments that? enabled the reported casualty to be classified as severe.

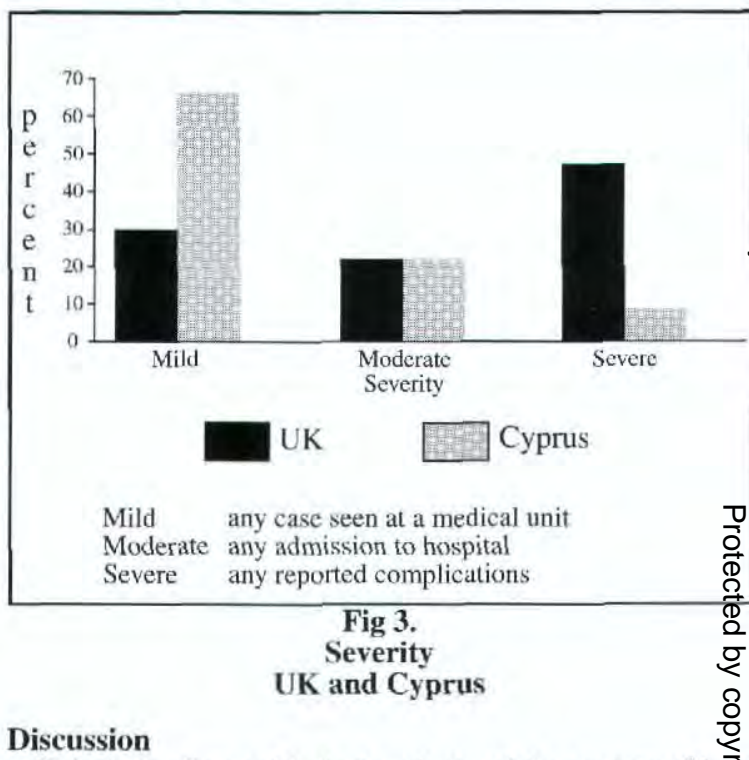

This is the first published analysis of the reports of hoilis casualties in UKLF for 1990-1994. Unfortunately th paper relies on the retrospective analysis of the data and is therefore subject to many potential biases. The figures for 1986-1989 were collected by an investigator at Medical $\overrightarrow{\vec{\rho}}$ Branch, UKLF with an interest in climatic injury. It is 3 likely that these figures are a reliable reflection of the reported cases. The low figures for 1990-1993 are veryo. different from the remaining totals. There was ans increased emphasis in policy in 1990 with the publication of revised instructions (3). This may have reduced the exposure of soldiers to the risk of heat illness during this period. But under reporting has to be considered as theo most likely reason for this variation in the numbers of reports. This was also the period of the Gulf War and the implementation of 'Options for Change'.

The source of reports for 1994 shows a substantialo variation across the country and some units which would be expected to produce heat casualties due to the nature of their training (eg 5 Airborne Brigade) do not feature. I has to be concluded that the current reporting system in UKLF does not cover all heat casualties that occur. In $N$ spite of the limitations of the reporting system at least $8 \mathrm{I}_{\mathrm{N}}^{\mathrm{N}}$ heat casualties did occur in 1994. It is not possible to determine a denominator for the total number of soldiers $\omega$ exposed to the risk of heat injury in UKLF and thus an annual incidence cannot be derived. The risk will varyo 
substantially from those personnel whose employment is essentially sedentary to those who undergo a form of physical selection testing for specialist employment. Therefore a single figure for incidence cannot reflect the risk to an individual of becoming a heat casualty because of this wide variation in employment.

The comparison between UK and Cyprus reflects different populations. The UK military population is substantially larger than the Cyprus military population and so the absolute incidence has to be very different. A comparison based on percentages still highlights similarities and differences between the two groups. It also shows that a policy aimed at reducing the incidence of heat casualties has been different in each Command.

The monthly distribution of cases confirms that the environmental temperature is a significant factor in the generation of heat casualties because the majority of casualties occur during the summer months. However this is not the sole factor. Heat casualties are reported during the winter months when the ambient temperature is unlikely to be relevant. Furthermore the improved weather conditions of the summer months will increase the activities that soldiers undertake and therefore more soldiers will be exposed to the risk of becoming a heat casualty in the summer months compared to the winter. Thus it is not possible to draw the single conclusion that environmental heat is the primary factor causing heat casualties in soldiers.

Heat storage in the human body is the result of the generation of metabolic heat during exercise less the loss of heat to the environment. The primary cause of heat casualty reports in UK is military runs with forced marches and ICFTs as significant additional causes. The common denominator in these is high intensity exercise. In Cyprus there are strict guidelines regarding these activities and the primary cause is military exercises. It is harder to provide detailed advice for commanders about appropriate activity levels in these circumstances. The soldiers who became casualties in Cyprus were most often from visiting units and unacclimatised and therefore it is this subgroup to whom any revision of existing policy should be directed.

The distribution of severity also shows a difference between UK and Cyprus. The figures from Cyprus are based on reports from a single medical centre and are known to include all cases presenting. The UK figures are less reliable and is highly likely that there is a significant reporting bias for the more serious cases. However the absolute number of serious cases has to be carefully considered because a prevention programme must primarily aim to reduce these cases.

\section{Conclusions}

The Army has an existing policy for the prevention of heat casualties (3). This paper shows that heat casualties remain an important cause of morbidity in the Army in spite of the current instructions. The relative contribution between environmental heat and metabolic heat in causing heat casualties will vary according to the circumstances Overall if it is considered important to reduce the absolute number of heat casualties occurring in the Army then it is $\mathbb{\Phi}$ necessary to focus on the reduction in incidents occurring in temperate climates with a relatively low environmentalo temperature. In these circumstances intense physicalo exercise of moderate duration ( $1 / 2-2$ hours) is the primary cause. Clothing and individual factors (eg. physical fitness $\stackrel{?}{+}$ and concurrent illness) are more important than the environmental temperature per se. Overseas Commands in hot areas (eg Cyprus) need to develop separate policies? for the prevention of heat casualties which may well have $\mathbb{Q}$ detailed instructions on the measurement of environ-» mental temperature.

This paper shows that the physiological effects of forced marching and the ICFT need to be further $\vec{\omega}$ examined. The absolute incidence of cases occurring? during the activities (cases per soldier exposed to the activity) should be studied to determine the specific circumstances that lead to heat casualties. It may be that $\vec{A}$ certain combinations of clothing, speed, hydration and environmental temperature can be identified that are highN risk. This would enable the development of precise guidelines for these activities. Such studies could easilyo be undertaken at training units where these activitions occur regularly.

This paper demonstrates the potential value of a cent reporting system to monitor trends in the health of tife Army. Such a scheme has been recommended by otkis authors $(1,2)$. It is only by the analysis of this type \&fo information that the need for refinements in existifg policy can be identified and justified. This type ôf reporting system can also highlight gaps in existi knowledge and lead onto focused and worthwhile research programmes. It is often frustrating for primary care professionals to complete health related returns and it $\overrightarrow{\vec{\theta}}$ is the duty of the recipients of these returns to ensure that 3 the information provided is collated and acted upon.

\section{Acknowledgements}

My thanks go to Maj S Drysdale for providing access to the heat casualty reports for UKLF for 1990-1994. My thanks also to Lt Col TP Finnegan for use of data on heat casualties 1986-1989.

\section{REFERENCES}

1. Dickinson JG. Heat illness in the Services. $J R$ Army Med Corps 1994; 140: 7-12.

2. FINNEGAN TP. Heat illness in the Services. IR Army Med Corps 1995; 141: 161-162.

3. Defence Council Instruction JS $24 / 90$. Heat injury, itso prediction, prevention and treatment. HMSO. 1990.

4. PORTER AM. Heat illness and soldiers. Milit Medo 1993; 158: 606-609.

5. FINNEGAN TP. Climatic illness of soldiers in the 0 United Kingdom. 23rd International Congress on Occupational Health. Montreal 1990.

6. BRICKNELL MCM. Heat illness in Cyprus. Iñ preparation. . 